\title{
ALICANTE: UNA CIUDAD DE LA CORA DE TUDMIR
}

\author{
A. Ramos Hidalgo \\ Departamento de Geografía Humana \\ Facultad de Filosofia y Letras \\ Universidad de Alicante
}

Las siguientes notas tratan del carácter geográfico que prevalece en el origen y consolidación urbana de Alicante en su emplazamiento del cerro Benacantil tras el Pacto de Tudmir en los momentos iniciales de la dominación musulmana. Constituyen una reflexión sobre el conjunto de elementos de la estructura urbana, por escasos o embrionarios que fuesen, que configuraban su porte ciudadano.

\section{LA CIUDAD MUSULMANA}

El establecimiento de la ciudad de Alicante en su emplazamiento actual, su cronología y las razones concretas que motivan la fundación son cuestiones difícilmente dilucidables pues se carece de documentación escrita al respecto. No obstante pueden aventurarse ciertas hipótesis de carácter geográfico e histórico aunque con ellas no pretendamos en ningún caso el valor de la demostración total.

Las referencias arqueológicas de precedentes ocupacionales en el monte Benacantil (1) y sus faldas, tanto de carácter defensivo como

(1) E. LLOBREGAT: Gran Enciclopedia de la Región Valenciana I, (s.u. Alicante), pág. 174 y s. Iniciación a la arqueologia alicantina, pág. 106. El poblado de la cultura del Bronce valenciano de la Serra Grossa, Alicante, Pap. lab. arq. Valencia 6, 1969, págs. 31 y ss. Contestania lbérica, pág. 112. 
residencial, que abarcan desde la Edad del Bronce hasta la época Tardorromana niegan, por su parte, la idea de la fundación de Alicante en su actual localización con un estricto punto de partida desde la época musulmana.

La topografía y el valor defensivo que de ella se deriva y no la fertilidad, similar en toda la zona, son los factores que favorecen el cambio de emplazamiento de la ciudad romana desde la planicie de Benalúa hasta las faldas del Benacantil, por las obvias posibilidades defensoras que éste ofrece, situado sobre la misma línea del mar, frente a la llana plataforma costera benaluana de más incierta defensa.

El Alicante musulmán surge en fecha imprecisa tras el tratado o pacto de Teodomiro, en el que el Lucentum romano (2), con categoría de medina pasará a integrarse en el señorio de los Banu-Jattab, tras el matrimonio de un miembro de esta tribu, integrada en las tropas de conquistadores sirios de Balŷ, ábd-alŶabbār ibn Nadīr, con la hija de Teodomiro, al ocupar los yunds participantes en dicho tratado con Teodomiro las faldas meridionales del Benacantil y su antiguo fortín, ya que la religión islámica no permitía a los recién llegados convivir en la misma ciudad con los hispanorromanos. Por otra parte no poseemos ningún testimonio que nos evidencie el asentamiento de estos ejércitos en el Benacantil, a excepción del dato gentilicio que nos proporciona Ibn Hazam (3) sobre la familia de los Banu-Al-Saij, descendientes de los Qanía, de la rama de los llyas y de los Mudar, que según Guichard (4) serían árabes del norte $y$, por supuesto, no pertenecientes a los sirios de Balý que procedentes del N. de Africa se asentaron en estas zonas.

El auge social y económico de la nueva comunidad contrasta con el debilitamiento, hasta la total consunción, de la antigua Lucentum (5); de cualquier manera no debió ser ajeno el origen del Alicante musulmán a la acentuada tendencia del mundo hispanoárabe descrita por Lacarra (6) a fundar nuevas ciudades.

Escasas y dispersas son las referencias de autores árabes sobre la naciente ciudad, a veces limitadas a estrictas indicaciones de equidistancia con otros lugares, incluso las diferentes formas existentes de nominarla, Lakant-al-Hosun (¿castillo?), Lakant-al-Kubra (¿Alcodre?) y Lakant-al-Sugra y que no deben ser otra cosa más que meras referen-

(2) E. LLOBREGAT: Hacia una desmitificación de la Historia Antigua de Alicante. Nuevas perspectivas sobre algunos problemas, R.I.E.A., 1969, págs. 35 y ss. Teodomiro de Oriola págs. 35 y ss.

(3) "Kitab...", apud. E. TERES, Linajes árabes en Al-Andalus, AA, 22, 1957, pág. 95.

(4) P. GUICHARD: Al Andalus, pág. 321. Barcelona, 1976.

(5) E. LLOBREGAT: Teodomiro de Oriola, pág. 32. Alicante, 1973.

(6) J. M. LACARRA: Panorama de la historia urbana en la peninsula ibérica desde el siglo $V$ al $X$, págs. 56 y s. Valencia, 1971. 
cias indicativas a su situación en las rutas comerciales o diferenciación expresa entre los edificios de la ciudad y el ámbito del castillo, plantean aún hoy problemas de localización definitiva, como los aducidos por J.M. Del Estal (7).

R. Azuar indica que, con toda seguridad, el nuevo emplazamiento y sus pobladores debieron sufrir los efectos de la razzia normanda del año 858-859 y que padecerían las consecuencias de la continua inestabilidad política del área, tras lo que a principios del siglo $X$ participaría, ideológicamente, de la general desobediencia al poder Omeya del recién instituido Califato. Reflejo de ello, es la sublevación de Al-Saij-alAslami en 924 contra Abd-Al-Rahman III referida por Ibn Hayyan (8).

Coetáneamente a estos hechos la descripción geográfica de AlIstajari y más tarde la de Ahmed-al-Razi nos proporcionan referencias de la ciudad y del castillo, al escribir sobre la Cora de Tudmir: «...el otro es Alicante que yaze en la sierra de Benalcaal, e della salen otras muchas sierras en que fizieron muchas villas buenas, en que labraban muchas buenas (tierras y tejen) telas de paños de seda e los que y moravan heran malas gentes e de mala manera e heran sotiles en sus obras...» (9).

Por otra parte durante el dominio almorávide la ciudad adquirió un rango superior que contrasta con su escasa importancia anterior, atestiguada por la misma ausencia de citas que encontramos en los escritos de geógrafos y viajeros de fases anteriores. En este momento, a mediados del siglo XII (1154) la importancia de su actividad económica permite a Al-Edrisi describir más detenidamente el carácter y la riqueza de Alicante, así como algunos de los elementos de su organización urbana. La descripción de este autor menciona concretamente el nuevo emplazamiento de la ciudad musulmana, nos dice que... «...Alicante es ciudad poco importante pero de bastante población. Hay en ella un mercado, una mezquita mayor y otra menor. El esparto que allí crece se exporta a todos los países marítimos. El suelo produce frutas y legumbres en abundancia y principalmente higos y uvas. Es muy fuerte el castillo que defiende a esta ciudad y difícilmente puede treparse hasta él. A pesar de su poca importancia, Alicante es un lugar donde se construyen buques para el comercio y barcas. En sus inmediaciones, por el lado de occidente, hay una isla que lleva el nombre de Plana;

(7) J. M. ESTAL: Conquista y anexión de las tierras de Alicante, Elche, Orihuela y Guardamar al Reino de Valencia por Jaime /l de Aragón (1296-1308), pág. 57. Alicante, 1982.

(8) R. AZUAR: Castellologia medieval alicantina, págs. 192 y s. Alicante, 1981.

(9) D. CATALAN y M. DE ANDRES: Crónica del moro Rasis, págs. 35 y s. Madrid, 1974. 
está de la costa a una milla de distancia y en este excelente puerto es donde se ocultan los navíos de los enemigos..." (10). Con referencia a la mencionada actividad constructora de embarcaciones R. Azuar (11) supone que Alicante aportaría naves de ataque y apoyo para la campaña marítima de la toma almohade de la isla de Mallorca, en manos de la "Ganiya" almorávide, hecho de armas que partió del puerto de Denia en 1203. En cuanto, al castillo podemos suponerlo incurso en los procesos de rearme de la zona en los siglos X y XI descritos, entre otros, por M. Epalza (12), y R. Azuar (13).

Por último entre otras noticias de índole política referidas a Alicante durante el último período de la dominación musulmana figura la propuesta que recibió Jaime I en 1242 en el lugar de Bayrén, al N. de Denia, del último señor de Valencia y Denia, Ibn Zayan del intercambio de Alicante, que aún poseía, por la isla de Menorca (14).

En lo referente a su status (15) jurídico parece que la denominación de medina que se recoge en el Pacto de Tudmir no correspondería plenamente al caserío que se instaló en el Benacantil que era propia de ciudades más importantes. Más que esto último Alicante estaría comprendida en una unidad jurisdiccional distinta, el iqlim, de carácter plurifuncional, no exclusivamente agrícola que abarcaba un espacio más amplio en el que existía un indeterminado número de castillos, aldeas, alquerías, raales y huertas, a los que se les fijaba en común sus impuestos. Por ello, Alicante mantendría con su territorio circundante unos lazos de comunidad homogénea al cual, a lo sumo, prestaria servicio defensivo con su castillo (16).

Hasta aquí hemos descrito las secuencias fundamentales de la trayectoria histórica de la ciudad musulmana mencionadas en las fuentes de referencia, menos evocadoras o explícitas que las de otras ciudades coetáneas de relativa proximidad geográfica (17). Pero si escasas son esas referencias otro tanto podemos lamentar de lo relacionado con los

(10) AL IDRISI apud. GARCIA MERCADAL: Viaje de extranjeros por España y Portugal, I, pág. 195. Madrid, 1952.

(11) R. AZUAR: Op. cit., pág. 197.

(12) M. EPALZA: Notas sobre el lingüista lbn Sidah y la Historia de Denia y su región en el siglo XI, R.I.E.A., 15, 1981, págs. 163 y ss.

(13) R. AZUAR: Op. cit., pág. 197.

(14) J.M. ESTAL: Op. cit, pág. 57 y ss. Llibre des feits de Jaime l, ed. F. SOLDEVILLA, Les quatre grans cróniques, pág. 120. Barcelona, 1971.

(15) H. MUNIS: La división politico administrativa de la España musulmana, R.I.E.I., V, 1957, págs 79 y ss.

(16) P. GUICHARD: La Valencia musulmana apud Nuestra Historia, II, pág. 264. Valencia.

(17) Cf. V. ROSELLO y G. M. CANO: Evolución urbana de Murcia; Murcia, 1975. V. GOSALVEZ: La ciudad de Elche. Valencia, 1976. 
vestigios arqueológicos, exponentes de la vida material de la ciudad. Sin posibilidades de una sistemática excavación arqueológica, al estar ocupado el recinto islámico por el caserio de los barrios altos, pocas son las posibilidades de encontrar referencias materiales del antiguo Alicante Islámico, sobre todo si a ello añadimos las catastróficas destrucciones sucesivas producidas en actos de guerra, como las de la castellano-aragonesa (de los dos Pedros), el bombardeo por la escuadra francesa de 1691, la voladura de parte del cerro y del castillo durante la guerra de Sucesión, así como los desprendimientos rocosos o los necesarios trabajos de reacondicionamiento de las vertientes meridionales del castillo efectuados durante el siglo XIX.

Cabe señalar además el hecho de que el escaso valor de cambio de este espacio urbano en la actualidad le ha impedido entrar en el proceso del comercio de solares. En consecuencia son poco frecuentes las nuevas edificaciones en el área, por lo que el azar de descubrimientos arqueológicos en la excavación de cimientos se reduce.

Pese a la escasez de hallazgos, R. Viravens (18), F. Figueras Pacheco (19) y M. Rico (20), mencionan la aparición de cerámica, monedas y pavimentos árabes, sin más precisiones, en el recinto de la ciudad musulmana, a los que debe añadirse los obtenidos al excavar refugios en la pasada contienda civil, a los encontrados al derruir viejas casas y que suelen conservarse en colecciones particulares, por ejemplo, los aparecidos en la calle Instituto, en el barrio de la Villa Vieja (21).

En la vertiente meridional del monte Benacantil, beneficiándose de la solana y cara al mar, la ciudad dispondría de un reducido espacio para instalarse desde la playa hasta la curva de nivel de los 50 metros del cercano abrupto, adaptándose a una irregular topografía sobre la que incidía el excavado de sucesivos barrancos que recogían los arrastres de la lluvia caida sobre el cerro y que bajaban directamente hacia el mar a través del caserío, tal es el caso de la actual plaza de Santa María. - Supondría un punto de humor que el nombre de Niágara que recibe la calle trazada con posterioridad continuando su circuito a más baja cota que la plaza le fuera otorgado en virtud de los mencionados arrastres de lluvia-.

Otro de estos barrancos está ocupado actualmente por la calle de San Rafael. Asimismo la calle de Labradores y el barranco inmediato

(18) R. VIRAVENS: Crónica de Alicante, pág. 26, ed. facsimil de la de 1876. Alicante 1976.

(19) F. FIGUERAS PACHECO: Compendio histórico de Alicante, pág. 92. Alicante, 1957.

(20) M. RICO: Memoria relativa a los nuevos descubrimientos de la Antigua Lucentum, pág. 47. Alicante, 1958.

(21) G. VIDAL TUR: Alicante, sus calles antiguas y modernas, pág. 39. Alicante, 1974. 
por occidente (Vall Barranquet, actual Rambla de Méndez Núñez) recogían las aguas del tramo occidental de la montaña.

Pese a los sucesivos acondicionamientos del terreno, rellenado de taludes, reforzamiento con muros de los declives, desmontes y la construcción de aterrazamientos sucesivos para una más adecuada instalación del caserío posterior, todavía resultan evidentes las iniciales condiciones del terreno, especialmente los días en que lluvias de fuerte incidencia horaria producen verdaderos torrentes en las calles mencionadas.

Por encima de la curva hipsométrica de 50 metros el abrupto del monte se muestra inadecuado para la edificación del caserío, razón que provoca su desaparición al pie mismo de los cantiles para ceder paso en la cumbre a la fortaleza militar.

\section{LAS MURALLAS}

Sin restos evidentes de la primitiva muralla que la ciñó y con la vaga y contrapuesta información que nos ofrecen conocidos cronistas e historiadores de la ciudad, resulta muy dificultoso el intento de reconstruir el perímetro de la misma. Bendicho (22) menciona las murallas indicando tan sólo la existencia, a mitad de la sierra, de un antiguo "muro de tapias fortíssimo que sirve la fortaleza antigua y baja a la Villa Vieja"; mientras que Viciana (23) sólo habla de las murallas construidas en el siglo XVI. Por otra parte N. Camilo Jover (24) delimita el emplazamiento de la ciudad desde la antigua ermita de la Virgen del Socorro hasta la plaza de Ramiro a la vez que señala que su muralla venía a parar a la puerta Ferrisa, obteniéndose de su apreciación un perímetro urbano demasiado reducido. No más explícito, Viravens zanja la cuestión situando la ciudad a..entre la parte más elevada y hasta la playa del Postiguet, con una prolongación hacia el Arrabal Roig...” y con la muralla cerca de la puerta Ferrisa (25). Figueras Pacheco (26) tampoco centra el problema, aún cuando su deseo de valorar los hechos de la conquista cristiana y la subsiguiente "creación" de una Vila Nova, frente a la Vila Vella musulmana le animen a trazar un perímetro de la muralla. Para ello se basa en el seguimiento documental de la sesión de Cortes celebrada el día 21 de noviembre de 1265 en Alicante por el

(22) V. BENDICHO: Crónica de la muY ilustre noble y leal ciudad de Alicante, pág. 39, el. abreviada. Alicante, 1960.

(23) M. DE VICIANA: Crónica de la ínclita y coronada ciudad de Valencia, III, pág. 347. Ed. facsímil de la de 1564. Valencia, 1972.

(24) N. C. DE JOVER: Reseña histórica de la ciudad de Alicante, pág. 23. Ed. facsímil de la de 1863. Alicante, 1978.

(25) R. VIRAVENS: Op. cit., pág. 24.

(26) F. FIGUERAS PACHECO: Op. cit, pág. 93. 
monarca aragonés Jaime l en la iglesia "Novella de Fora" (San Nicolás). Según afirma este autor el trazado de las murallas que desde el castillo ceñían la ciudad bajando hacia el mar por el E. incluía el «antiguo muro de tapias fortísimas» que mencionó Bendicho y al O. por otro situado "más o menos entre las actuales calles de San Nicolás y San Agustín", con lo que el antiguo templo de San Nicolás quedaba fuera de ellas.

La insuficiencia de estas apreciaciones nos permiten considerar con $\mathrm{S}$. Varela y J. Calduch (27) más apropiado y real un desarrollo longitudinal de la muralla árabe que incluye dentro de la "villa murada" los elementos formales que característicos de la organización urbana musulmana, por embrionaria que ella fuese, a los que se refirió en la segunda mitad del siglo pasado Guardiola Picó (28) al analizar las bases del asentamiento de la primitiva ciudad.

En apoyo de este último criterio existen dos referencias gráficas complementarias: el croquis que el municipio adjuntó en 1656 al Rey con el memorial de peticiones de mejora de las defensas de la ciudad y el plano de Castellón y Valero de 1688 que incluyen un proyecto, no realizado, de rectificación y ampliación de murallas de corte típicamente renacentista por su configuración geométrica. En ninguno de ambos planos figura trazado el itinerario antiguo que describen los cronistas por lo que se hace difícil su comprobación, aunque el hecho, constatable en muchas ciudades, de la perduración de su traza originaria en el entramado del callejero actual, apenas afectado por las sucesivas oleadas constructivas, y la propia memoria urbana de la toponimia local permiten en último término su detección.

Lamentablemente, los dos planos de referencia omiten el callejero del interior de la ciudad, siendo el de Castellón y Valero, por otro lado, el que señala la trayectoria de un muro que descendiendo de la muralla abraza al castillo en la divisoria de aguas del contrafuerte occidental del Benacantil, bajaba en dirección meridiana hacia la playa, denominándolo como "del antiguo recinto de los romanos". Dicha muralla, según estos planos, se iniciaba en un cubo cilíndrico situado en el antedicho lienzo, al tiempo que dejaba fuera el actual barrio de Santa Cruz. Su trazado conectaba los recintos defensivos la Ereta y el Torreón de la Pólvora y desde él se dirigía hacia las cercanías de la plaza abierta ante la fachada principal de la Iglesia de Santa María en donde se encontraba situada la puerta Ferrisa, edificio notable, derruido en 1862, único que se conservaba de la época musulmana, según R. Viravens (29), aunque

(27) S. VARELA y J. CALDUCH: Guía de arquitectura de Alacant, pág. 9. Alicante, 1979.

(28) J. GUARDIOLA PICO: Reformas en Alicante para e/ siglo XX. III, pág. 57. Alicante 1909.

(29) N. CIRAVENS: Op. cit., pág. 24. 
de su construcción primitiva quedase bien poca cosa, tan sólo «el arco que miraba a la calle Mayor, acreditado por su forma y colocación de los sillares", así como por la inscripción coránica cuyos caracteres, casi borrados, se distinguían en torno a su clave (30).

Estaba esta puerta - iabierta al camino de Elche?- emplazada en una pequeña meseta a cuyo pie el mar formaba una herradura (31), recordando su nombre las diversas portes ferrices (32) que existieron en el siglo XIII en Tarazona, Murviedro, Morella, Lérida, Barcelona, Galipolis o Perpiñán. Desde esta puerta la muralla del primitivo recinto de la ciudad iría discurriendo hacia el NW., por la calle y plaza de Lonja de Caballeros, plaza de la Santísima Faz, San Agustín, Montengón, Stos. Médicos y San Cristóbal, hasta la puerta de la Huerta, al N., desde donde enlazaria con el lienzo y baluartes del anteriormente mencionado contrafuerte occidental del Benacantil (33).

Más al E., de la puerta Ferrisa existiría un reducido espacio urbano cada vez más estrangulado, sobremontando la playa, en el que quedaría incluida la ubicación de la Mezquita Mayor, en el solar ocupado por la actual iglesia de Santa María, que volvería a estar limitado por un nuevo lienzo de murallas ascendente hacia el castillo desde la misma puerta que en los planos de la ciudad del siglo XVII se sitúa junto a la plataforma del Espolón y el torreón de San Sebastián, denominada Puerta Nueva y Puerta de la Huerta en el de Mirallas, de finales del siglo XVIII.

Resulta difícil, a la luz de los escasos datos disponibles, interpretar el sentido urbano del muro descendente desde la Ereta hasta la puerta Ferrisa, si es que su construcción realmente puede situarse en la época de la ciudad musulmana. No estamos en condiciones de asegurar que sirviera para separar "barrios", comunidades religiosas - ¿mozarabía de Alfonso I de Aragón?-, o étnicas diferentes - igrupos de comerciantes o marineros de las ciudades italianas?-, áreas de actividad distinta o si, por el contrario, era un mero elemento más de defensa urbana.

Dentro del mencionado perímetro, entre el mar y la pared montañosa coronada por el castillo se guarecía una ciudad de reducida di-

(30) N.C. JOVER: Op. cit., págs. 23 y s.

(31) L. MAS y GIL: ed. Informe incompleto sobre Alicante. Año 1804, pág. 40. Alicante, 1972.

(32) F. FIGUERAS PACHECO: Geografia general del Reino de Valencia. Provincia de Alicante, pág. 473. Barcelona, s. a.

(33) S. VARELA y J. CALDUCH: Op. cit., pág. 9. 
mensión, dispuesta a modo de anfiteatro en el espacio comprendido entre el escarpe occidental del Benacantil, donde estuvo situado el antiguo fuerte llamado de la Ampolla y el Espolón, dispuesto sobre la playa del Postiguet. La naciente ciudad tuvo que soportar las condiciones geológicas y topográficas, que favorecian la defensa, pero a la vez hacian necesarias frecuentes operaciones de acondicionamiento del terreno para salvar pendientes o evitar barrancos en el paulatino proceso de instalación del caserío, articulado en una trama viaria que desde el espacio, protegido por las alturas de la Ereta, correspondiente a la plaza del Pont conectaba con las defensas periféricas ubicadas en las cercanías de la plaza de San Cristóbal y la trasera de la iglesia de Santa Maria. De esta forma la ciudad se extendía desde la citada plaza del Pont, considerada centro y origen del Alicante musulmán por Guardiola Picó, Varela y Calduch (34), por el sector ocupado por los barrios altos de la ciudad que tras la Conquista conservará el nombre de Villavieja hasta nuestros días y desde donde se produciría su expansión hacia el inmediato barrio del Carmen.

\section{EL CALLEJERO}

La estructura viaria, a causa tanto de los impedimentos físicos como de la organización urbana y de los mismos elementos culturales islámicos, fue desarrollándose sin un bosquejo previo, dando lugar a calles sinuosas con alteraciones que afectaban en los diferentes tramos a la anchura, alineación y pendiente; adaptadas las principales al trazado de las curvas de nivel y uniendo en su recorrido las puertas de la muralla o encaminándose a la Mezquita Mayor, otras, por el contrario, perpendiculares a éstas bajaban en dirección a la playa.

La mínima entidad de las escasas plazas que se abrían en esta rudimentaria trama eran la mayor parte consecuencia de la mera intersección de las calles principales. Nada sabemos de azucaques o adarves ni siquiera de arcos sobre las calles existentes en la ciudad desaparecidos acaso al mismo tiempo que la vieja muralla y por el reacomodo del caserío.

El callejero actual podría mantener algunos de estos ejes viarios principales como el trazado por las calles Villavieja, Maldonado, plaza de Quijano y Carmen hacia la puerta de la Huerta, al NO., de la muralla, o a una cota superior, el formado por las calles Balseta, plaza del

(34) J. GUARDIOLA PICO: Op. cit., pág. 62; S. VARELA y J. CALDUCH: Op. cit., pág. 47. 
Puente, Toledo, plaza del Carmen con parecido final o, incluso, más arriba el eje San Juan, Lepanto, San Roque..., todos ellos con la común característica de contornear manzanas alargadas y estrechas.

\section{LA ESTRUCTURA}

Difícil es, asimismo, aventurar opinión sobre cuestiones relacionadas con estructura urbana, espacios de diferenciación funcional, etc., pero si en el esquema trazado hasta ahora entrevemos los cánones urbanísticos de la época, no resultaría arriesgado localizar el zuq que mencionaba El Edrisi (35) en la plaza existente junto a la Mezquita Mayor, cercana, por tanto, a la puerta Ferrisa, a más baja cota que ambas y próxima a la playa, espacio libre mantenido hasta el presente, que ocupa la plaza de Ramiro.

La mencionada Mezquita Mayor, situada al SW., de la población, sobre una elevación del arranque meridional del cerro recibiria la primera de las vías principales arriba citadas. Ocupaba el mismo solar que la actual parroquia de Santa Maria, con cuyos cimientos se confunden los del antiguo templo musulmán (36), como quedó de manifiesto al aparecer restos de la puerta de la mezquita bajo la escalera de acceso a la sacristía en el curso de unas reparaciones (37).

El otro lugar religioso descrito en el texto de El Edrisi no es de exacta localización. Podría situarse en las instalaciones defensivas del Benacantil o, mejor, a extramuros, cerca de la actual iglesia concatedral de San Nicolás, puesto que Viravens (38) asegura que al abrir los cimientos de las casas construidas al $\mathrm{S}$., de la mencionada iglesia, en el siglo XVI, aparecieron vestigios de las pilas de ablución.

No se ha localizado el emplazamiento de baños, conocidos, no obstante, por la documentación alfonsina (39), la posterior medieval (40), y una cita de Bendicho (41), sobre los que a mayor abundamiento se hace impensable su existencia dada la prioridad otorgada a este tipo de instalaciones en el mundo musulmán, sobre todo habida cuenta de

(35) AL IDRISI: Op. cit, en nota 10.

(36) F. FIGUERAS PACHECO: Op. cit., pág. 93.

(37) G. VIDAL TUR: Op. cit., pág. 39.

(38) R. VIRAVENS: Op. cit., pág. 21.

(39) Córdoba, 29 de junio de 1260. CODOM III, Dto. LIV, pág. 73.

(40) A.R.V. Real Patrimonio, Maestre Racional, 4543 (año 1376)... «ltem, fa en la festa de Nadal En Jacme Escuder, per I casal de banys situat en la dita vila, $X$ sous".

(41) V. BENDICHO, op. cit., pág. 65. 
que a la ciudad entraban conducciones de agua procedentes de los manantiales de la Fuensanta (42).

En las afueras de la misma existía un cementerio árabe, bordeado por la carrera de Murcia, "junto al barranco" (43), donado a un vecino de Alicante, tras la conquista cristiana, por el Obispado de Cartagena. Su emplazamiento debía estar situado junto al mihrab o recinto religioso de segundo orden antes citado. Los campos de los alrededores dispondrian probablemente de algunas rábitas o tumbas de santones. Estos mismos campos anteriormente lugar de asentamiento de villae rusticae romanas (44) habrian sido ocupadas por alquerías, almunias, y pequeñas aldeas, como queda manifiestamente expresado en los documentos de la conquista cristiana que se refieren «a los moros de la Huerta" donde se darían los cultivos conocidos como habituales en la época, citados por Escolano (45).

\section{LA POBLACION}

Es imposible conocer el número de habitantes con datos estadísticos pero sí por medio de aproximaciones basadas en el área del recinto urbano. Tales evaluaciones son debidas a Torres Balbás (46) y siguiendo el método del mismo otros autores han podido calcular los habitantes de Murcia y Elche respectivamente (47).

El método seguido por ellos parte del número de miembros considerado por familia y de la superficie media de la casa musulmana, con lo que se obtiene la densidad urbana y, por consiguiente, el número de habitantes de la ciudad.

Como cada casa musulmana tendría una media de 172 metros cuadrados y cada familia estaría compuesta de 6 integrantes (personas) se obtiene una densidad por hectárea de 348 habitantes. En Alicante, aceptando la hipótesis de una superficie máxima de $7 \mathrm{Ha}$. en el interior de la vila se obtiene una población de unos 2.436 personas y unas 406 casas al finalizar el período islámico.

(42) V. MARTINeZ MORELLA, Privilegios y franquezas de Alfonso $X$ el Sabio a Alicante, pág. 28. Alicante, 1951.

(43) CODOM II. A.C. Murcia. Perg. orig., 15, págs. 19 y s.

(44) E. LLOBREGAT: Notes per a un estudi del poblament rura/ de la provincia d'Alacant entre e/ Baix Imperi il'Edat Mitjana, págs. 349 y ss. I Congreso Historia País Valenciano. II, 1980.

(45) G. ESCOLANO: Década primera de la ciudad de Valencia. Libro VI col. 81.

(46) L. TORRES BALBAS, Ciudades hispano-musulmanas. Págs. 93 y ss. Madrid, s.a.

(47) V. M. ROSELLO, G. M. CANO, Op. cit., pág. 44. V. GOZALVEZ: Op. cit., págs. 35 y s. Ed. facsímil de la de 1610. Valencia 1972. 


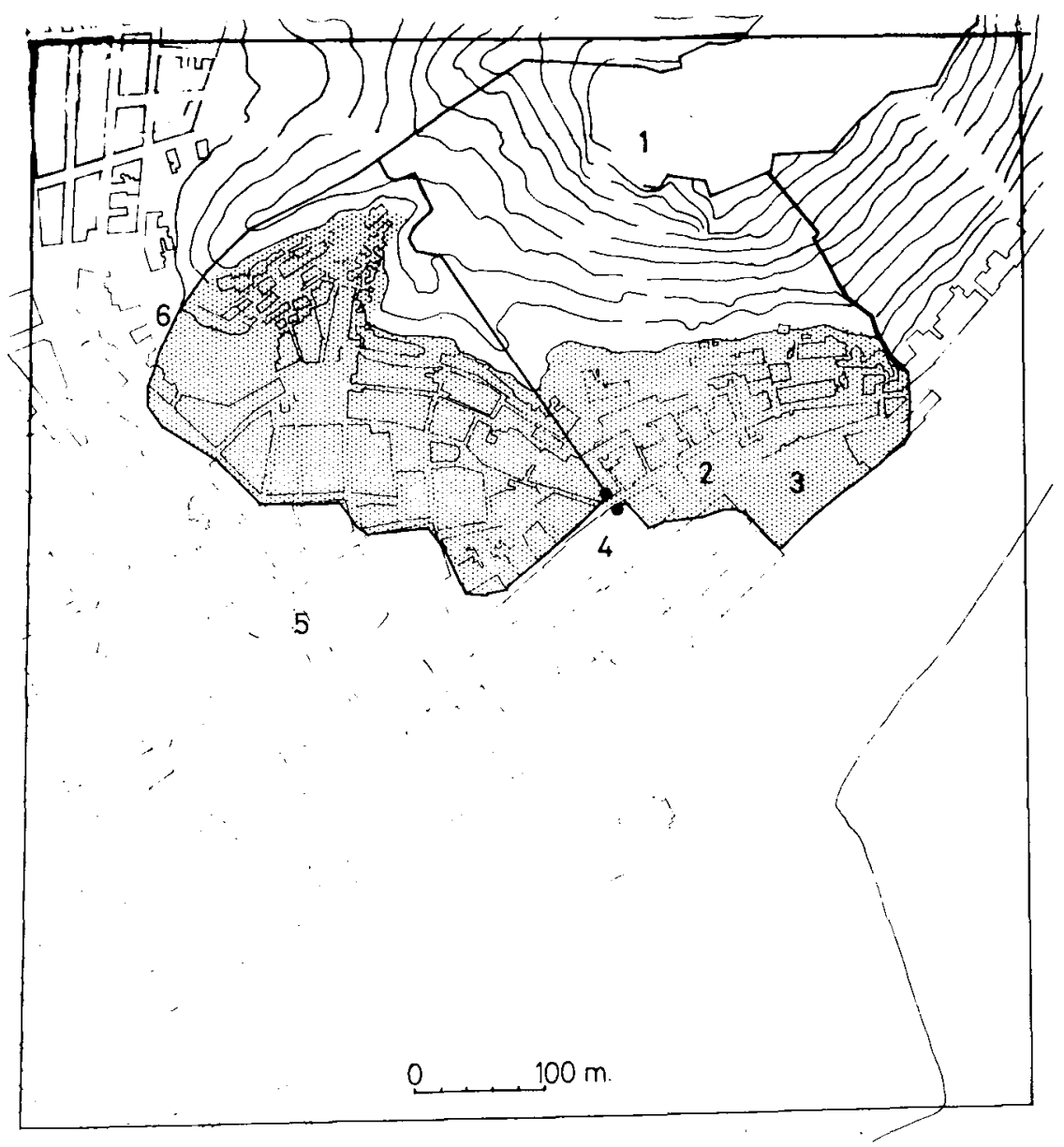

POSIBLE EXTENSION DE LA CIUDAD AL FINAL DEL PERIODO MUSULMAN
1. Castillo.
2. Mezquita.
3. Zoco.
4. Puerta Ferrisa.
5. Cementerio.
6. Muralla. 